\title{
PERLINDUNGAN HAK PATEN DALAM KAJIAN HUKUM ISLAM DAN PERAN UMAT ISLAM DALAM BIDANG IPTEK
}

\author{
Khoirul Hidayah \\ Fakultas Syariah UIN Maliki Malang \\ Email: Khoirul.hidayah@yahoo.co.id
}

\begin{abstract}
Abstraksi
Hak Paten adalah bagian dari hak atas kekayaaan intelektual (HKI). HKI sebagai hak yang timbul dari hasil olah pikir yang menghasilkan suatu produkatau proses yang berguna untuk manusia. Hak Paten merupakan bentuk reward yang diberikan terhadap seseorang dalam bentuk hak eksklusif. Jika ditinjau dari hukum Islam, keberadaan hak paten dibenarkan, namun tidak diperkenankan kalau hak paten yang sudah diperoleh hanya semata-mata untuk memperkaya diri sendiri. Minimnya jumlah paten negara Islam yang terdaftar di Dirjen HKI ataupun PCT menunjukkan betapa minimnya penelitian yang dilakukan oleh umat Islam. Padahal Al Qur'an telah banyak memberikan pesan agar manusia selalu berpikir menggunakan akalnya untuk menemukan segala. Sudah saatnya umat Islam harus bangkit di era globalisasi. Negara Islam harus mampu menunjukkan eksistensinya melalui riset dan teknologi, sehingga bisa mengungguli negara-negara Barat. Indonesia sebagai negara mayoritas Islam tentunya juga harus memulai eksistensinya dalam IPTEK yaitu dengan memulai melakukan penelitian-penelitian yang berbasis paten.
\end{abstract}

Paten is a part of Intelectual Property Rights (IPRs). HKI refers to product of human's intellectual that is beneficial for human being. Patent is a reward which is awarded to someone in exclusive form. In Islamic perspective, patent right is justified but it is forbidden to get patent merely for economic or financial interest. The inadequate number of muslim countries that are registered in HKI directorate general or PCT shows that only a few number of research conducted by muslims. In fact, Quran has sent its messages to human beings to use their brain in thinking to gather knowledge. This is the time for muslims to awake in this globalization era. Islamic states must be able to show their existences through research and technology in order they go beyond western countries. Indonesia as muslim majority country should start its existence in technology by conducting research which is patent-based.

Kata kunci: Hak paten, Umat Islam, IPTEK

Pada era globalisasi sekarang ini, tuntutan pengembangan terhadap ilmu pengetahuan dan teknologi menjadi isu utama dan fokus bagi negara-negara maju ataupun negara berkembang untuk bersaing guna memenuhi kebutuhan manusia yang selalu dinamis. Sebagaimana kita ketahui pada abad 21 ini secara jelas penguasaan Ilmu Pengetahuan dan Teknologi (IPTEK) masih banyak dikuasai oleh negara maju seperti Eropa dan Amerika.

Dunia Islam mengalami kemandekan intelektual yang cukup parah saat dunia Eropa begitu pesatnya mengembangkan ilmu pengetahuan dan teknologi. Akibatnya, selama 1 abad lebih dunia Islam dijajah oleh negeri-negeri Eropa. Meskipun kini dunia 
Islam telah terlepas dari penjajahan (politik), namun sisa-sisa penjajahan kapitalisme masih berakar kuat di dunia muslim. Akibat lemahnya ekonomi dunia Islam, sebagai akibat dari lemahnya IPTEK, akhirnya secara tidak langsung politikpun masih terjajah.

Berbicara masalah ilmu pengetahuan dan teknologi, jika dibandingkan dengan masyarakat Barat, umat Islam jauh tertinggal. Umat Islam senantiasa identik dengan kebodohan, bahkan sumber daya alam yang melimpah di negara-negara berpenduduk mayoritas muslim tidak bisa membuat rakyatnya makmur. Salah satu penyebabnya, adalah minimnya penguasaan teknologi sehingga berakibat ketidakmampuan dalam pengelolaan sumber daya alam yang dimiliki.

Perkembangan IPTEK sebuah segara tidak terlepas dari peran aktif dari proses berpikir manusia untuk mengetahui segala sesuatu di bumi ini (sebagai hasil ciptaan Tuhan) melalui penelitian-penelitian yang kreatif dan inovatif. Tidak dapat dipungkiri, bahwa yang sering melakukan kegiatan-kegiatan penemuan adalah lebih banyak dilakukan oleh negara-negara Barat yang mayoritas beragama non muslim, dan negara-negara Islam atau negara dengan mayoritas muslim hanya sebagai pengguna hasil temuan (teknologi) yang mereka hasilkan.

Pada bidang perlindungan hukum, tentunya perkembangan IPTEK sebuah negara dapat dilihat dari jumlah paten yang sudah di daftarkan di Dirjen HKI ataupun PCT (Patent Cooperation Treaty). Semakin banyak jumlah paten yang didaftarkan oleh satu negara, maka dapat dilihat seberapa banyak hasil teknologi yang sudah ditemukannya. ${ }^{1}$

Perlu dipahami bahwa hak paten merupakan salah satu bagian dari Hak atas Kekayaan Intelektual (HKI) yang merupakan terjemahan resmi dari Intellectual Property Rights. Ditjen HKI mendefinisikan HKI sebagai hak yang timbul dari hasil olah pikir otak yang menghasilkan suatu produk atau

${ }^{1}$ Insan Budi Maulana. Politik dan Manajemen Hak Kekayaan Intelektual. (Bandung: Alumni, 2009) h. 145 proses yang berguna untuk manusia. ${ }^{2}$

Perlindungan HKI di tingkat Internasional telah disepakati dalam bentuk perjanjian TRIPs (Trade Related Aspects of Intellectual Property Rights) di bawah administrasi Organisasi Perdagangan Dunia (World Trade Organization atau WTO). Pada tahun 1994 Indonesia telah meratifikasi keanggotaan WTO dalam Undang-Undang No. 7 Tahun 1994, dengan demikian secara otomatis TRIPs mengikat juga terhadap kebijakan nasional di Indonesia. Salah satu lembaga di bawah PBB yang mengurusi masalah paten termasuk pendaftaran PCT adalah WIPO (World Intellectual Property Organization).

Seiring dengan perlindungan paten terhadap hasil temuan inovatif manusia yang dipelopori oleh Negara mayoritas non muslim, apakah kemudian secara serta merta muncul pemahaman apa yang mereka lakukan hanya sekedar untuk kepentingan materialistis yang mana tidak sejalan dengan konsep dalam agama Islam. Apakah kemudian Negara Islam atau Negara mayoritas muslim menganggap bahwa paten adalah susuatu yang tidak penting. Pada penulisan artikel ini, penulis akan membahas bagaimanakah perlindungan hak paten jika ditinjau dari kajian hukum Islam dan bagaimanakah pengaruh perlindungan hak paten terhadap perkembangan umat Islam di bidang IPTEK.

\section{Perlindungan Hak Paten}

Hak Paten adalah bagian dari hak atas kekayaaan intelektual (HKI). Sebelum tahun 1945, paten diberikan di Indonesia berdasarkan undang-undang kolonial Belanda, Octroiiwet 1910. Setelah kemerdekaan, pada tahun 1979 Indonesia meratifikasi perjanjian dengan WIPO (World Intellectual Property Organization) yaitu badan PBB yang menangani urusan-urusan hak kekayaan intelektual. Selanjutnya pada tahun

${ }^{2}$ Ditjen HaKI dan ECAP II, bekerja sama dengan EC-ASEAN IPRs Co-operation Programme ECAP II, Buku Panduan Hak Kekayaan Intelektual dilengkapi dengan peraturan perundang-undangan di bidang HKI (Jakarta: Ditjen HKI dan ECAP II, 2006), h. 7 
1983, Indonesia masuk menjadi anggota Paris Convention. Pada tahun 1989 DPR mengesahkan Undang-Undang No. 6 Tahun 1989 tentang Paten. Selanjutnya mengalami perubahan menjadi Undang-Undang No. 13 Tahun 1997. Pada tahun 2001, pemerintah memperbaruhi UU Paten menjadi UU No. 14 tahun 2001. Hal tersebut dilakukan karena Indonesia harus menyesuaikan dengan perlindungan HKI dengan standar internasional yaitu melalui TRIPs.

Menurut pasal 1 angka 1 UU No.14 tahun 2001, Paten adalah hak eksklusif yang diberikan oleh Negara kepada Inventor atas hasil Invensinya di bidang teknologi, yang untuk selama waktu tertentu melaksanakan sendiri invensinya tersebut atau memberikan persetujuannya kepada pihak lain untuk melaksanakannya. Pengertian Invensi dan Inventor yang terdapat dalam pengertian di atas, menurut undang-undang tersebut, adalah: (1) Invensi adalah ide Inventor yang dituangkan ke dalam suatu kegiatan pemecahan masalah yang spesifik di bidang teknologi dapat berupa produk atau proses, atau penyempurnaan dan pengembangan produk atau proses. (pasal 1 angka 2 Undang-Undang No.14 tahun 2001); (2) Inventor adalah seorang yang secara sendiri atau beberapa orang yang secara bersamasama melaksanakan ide yang dituangkan ke dalam kegiatan yang menghasilkan Invensi (pasal 1 angka 3 Undang-Undang No. 14 tahun 2001).

Paten (patent) dalam bahasa Inggris berarti terbuka. Arti kata terbuka di dalam paten adalah berkaitan dengan invensi yang dimintakan paten. Terbuka dimaksud adalah karena semua rahasia invensi yang akan di daftarkan harus diuraikan dalam spesifikasi paten yang dilampirkan bersamaan dengan permohonan paten. Pada tahap pengumuman, informasi mengenai invensi yang diajukan paten tersebut, diumumkan kepada publik dengan cara dimuat pada Berita Resmi Paten oleh Dirjen HKI.

Hak yang diperoleh melalui paten adalah hak khusus untuk menggunakan invensi yang telah dilindung paten serta melarang pihak lain melaksanakan invensi tersebut tanpa persetujuan dari pemegang paten. Oleh karena itu, pemegang paten harus mengawasi haknya agar tidak dilanggar oleh pihak lain. ${ }^{3}$

Ada empat keuntungan sistem paten jika dikaitkan dengan perannya dalam meningkatkan perkembangan teknologi dan ekonomi: (1) Paten membantu menggalakkan perkembangan teknologi dan ekonomi suatu negara; (2) Paten membantu menciptakan suasana yang kondusif bagi tumbuhnya industri-industri lokal; (3) Paten membantu perkembangan teknologi dan ekonomi negara lain dengan fasilitas lisensi; (4) Paten membantu tercapainya alih teknologi dari negara maju ke negara berkembang. ${ }^{4}$

Disamping itu, sistem paten merupakan titik temu dari berbagai kepentingan yaitu kepentingan pemegang paten, kepentingan para investor dan saingannya, kepentingan para konsumen, serta kepentingan masyarakat umum. ${ }^{5}$

\section{Syarat-Syarat Paten}

Menurut pasal 2 Undang-Undang No. 14 Tahun 2001, paten diberikan untuk invensi yang baru dan mengandung langkah inventif serta dapat diterapkan dalam industri. Invensi bersifat baru, menurut pasal 3, suatu invensi dianggap baru jika invensi yang diajukan paten tersebut tidak sama dengan teknologi yang diungkapkan sebelumnya.

Untuk mengungkapkan apakah sebuah invensi bersifat baru, harus diadakan pemeriksaan terhadap data terdahulu untuk mencari dokumen pembanding yang terbit sebelum tanggal penerimaan permohonan paten. Apabila invensi yang dimintakan paten tidak terdapat dalam dokumen pembanding, invensi itu dianggap baru.

Penilaian ada tidaknya langkah inventif

${ }^{3}$ Tim Lindsey, dkk. Hak Kekayaan Intelektual Suatu Pengantar, (Bandung: Alumni, 2006), h. 183

${ }^{4}$ Ibid, h.185

${ }^{5}$ Ibid 
merupakan hal yang sangat sulit untuk dilaksanakan di dalam praktek. Sebagaimana ditetapkan di dalam pasal 3 suatu invesni mengandung langkah inventif jika invensi tersebut bagi seseorang yang mempunyai keahlian tertentu dibidang teknik merupakan hal yang tidak dapat diduga sebelumnya. Jika invensi tersebut berisi pemecahan masalah yang tidak berbeda dengan pemecahan masalah dari invensi yang terdapat dalam dokumen pembanding berarti tidak ada langkah inventifnya.

Saat ini terdapat beberapa perjanjian internasional yang mengatur tentang hukum paten. Antara lain, WTO Perjanjian TRIPs yang diikuti hampir semua negara. Pemberian hak paten bersifat teritorial, yaitu, mengikat hanya dalam lokasi tertentu. Dengan demikian, untuk mendapatkan perlindungan paten di beberapa negara atau wilayah, seseorang harus mengajukan aplikasi paten di masing-masing negara atau wilayah tersebut. PCT dibawah naungan WIPO adalah salah satu bentuk paten internasional, yang nantinya paten dapat didaftarkan melalui PCT dan mendapatkan pengakuan dari negara yang tergabung di dalam PCT.

\section{Pentingnya Penguasaan IPTEK Bagi Muslim di Era Globalisasi}

Eraglobalisasimerupakanerainformasi.Di era globalisasi ini, maraknya perkembangan teknologi telah menguasai dunia dan telah berhasil menyatukan batas wilayah negara melalui teknologi komunikasi. Hal ini tidak terlepas dari peranan ilmu pengetahuan yang semakin berkembang mengikuti perkembangan zamannya, dimana para ilmuwan dituntut untuk lebih produktif, inovatif dan berimprovisasi akan penemuannya sehingga mampu bersaing dengan penemuan-penemuan yang sudah ada. Kemajuan IPTEK dewasa ini telah memberikan kemudahan-kemudahan yang memanjakan kehidupan manusia dalam segala aspek, dimana pada mulanya manusia dengan berbudaya tradisional menjadi manusia pemikir yang analitis-kritis dan berketrampilan. $^{6}$

IPTEK merupakan dua sosok yang saling berkesinambungan satu sama lain. Dimana sains sebagai "body of knowledge" merupakan sumber teknologi yang mampu memberikan banyak kemungkinan munculnya berbagai ide-ide sebagai penemuan-penemuan baru ataupun penemuan rekayasa. Sedangkan teknologi adalah aplikasi dari sains yang dapat ditunjukkan dalam hasil nyata yang merupakan fenomena sosial buatan manusia. Teknologi tak akan pernah lahir tanpa manusia karena manusialah yang mengendalikan segala operasionalnya. ${ }^{7}$

Manusia adalah khalifah bumi sebagaimana dalam surat al-Baqarah ayat 30-33 dan surat al-Anbiya ayat 107 yang menjelaskan bahwa manusia diciptakan Allah untuk menjadi khalifah karena memiliki kemampuan berpikirdanbandingkandenganmakhlukciptaan Allah lainnya, misal malaikat. Manusia sebagai khalifah bumi tentunya harus mampu menghadapi segala permasalahan kebutuhan yang harus dipenuhinya. IPTEK adalah salah satu kebutuhan manusia yang harus menjadi perhatian bagi umat Islam.

Penguasaan IPTEK bagi muslim adalah mutlak adanya. Negara Islam atau negara dengan mayoritas muslim jangan hanya sebagai konsumen teknologi bagi negara Barat (mayoritas non muslim), namun harus mampu bangkit bersaing dengan mereka dan tidak hanya mengurusi politik dan perbedaan-perbedaan keyakinan ritual seperti antara kelompok sunni dan syiah, hal ini akan mengakibatkan umat muslim terpuruk dan tidak menjadi pelopor peradaban dunia sebagaimana Islam pernah pada kejayaannya pada masa Abbasiyah.

Adapun kemajuan yang dicapai umat Islam pada masa Dinasti Abbasiyah dalam bidang ilmu Pengetahuan, sainsdanteknologi

${ }^{6}$ Salim Rosyadi, Pandangan Sains dan Teknologi dalam Menghadapi tantangan Dunia Global, (www.uinsgd. ac.id) 16 Juni 2011

${ }^{7}$ Ibid 
adalah: ${ }^{\circ}$ (a) Astronomi, Muhammad Ibnu Ibrahim al Farazi $(777 \mathrm{M})$, ia adalah astronom muslim pertama yang membuat astrolabe, yaitu alat untuk mengukur ketinggian bintang. Disamping itu, masih ada ilmuwanilmuwan Islam lainnya, seperti Ali Ibnu Isa al Asturlabi, al Farghani, al Battani, al Khayyam dan al Tusi; (b)Kedokteran, pada masa ini dokter pertama yang terkenal adalah Ali Ibnu Rabban al Tabari pengarang buku Firdaus al Hikmah tahun $850 \mathrm{M}$, tokoh lainnya adalah ar Razi, al Farabi, dan Ibnu Sina; (c) I $1 \mathrm{~m} \mathrm{u}$ Kimia, bapak kimia Islam adalah Jabir Ibnu Hayyan (815 M), al Razi, dan al Tuqrai yang hidup pada abad ke $12 \mathrm{M}$ ); (d) Sejarah dan Geografi, pada masa ini sejarawan ternama abad ke $3 \mathrm{H}$ adalah Ahmad Ibnu al Yakubi, Abu Ja'far Muhammad Ja'far Ibnu Jarir al Tabari; (e) Ahli Bumi yang termasyhur adalah Ibnu Khurdazabah (913 H).

Pada era globalisasi tentunya umat Islam harus mampu mengembalikan kejayaan Islam sebagaimana pada masa Abbasiyah. Umat Islam sudah tidak diperkenankan malas melakukan penelitian dan hanya fokus bada ritual spiritual belaka. Umat Islam jangan terjebak pada permusuhan keyakinan dengan antar umat beragama, mereka harus mampu bangkit mengejar ketertinggalan teknologi yang dimiliki orang Barat dan mayoritas di dominasi oleh kaum non muslim. Penemuan teknologi dengan berbasis kemanfaatan umat oleh kaum muslim akan memberikan nilai derajat tersendiri di depan negara-negara Barat.

\section{Kajian Hukum Islam mengenai Perlindungan Hak Paten}

Manusia yang dapat menghasilkan paten adalah manusia yang selalu berpikir dan berusaha mencari solusi atas persoalanpersoalan yang dihadapi manusia guna memenuhi kebutuhah-kebutuhan hidupnya. Manusia selalu ingin berubah dan memperoleh kehidupan yang lebih baik. Hasil teknologi adalah salah satu indikator

\footnotetext{
${ }^{8}$ A. Raziq Naufal,Umat Islam dan Sains Modern, (Bandung: Husaeni, 1978), h. 46-47
}

bahwa sejauh mana kemampuan manusia mampu berpikir dan berusaha secara kreatif dan berinovasi. Paten adalah salah satu bentuk indikator dari hasil teknologi, semakin banyak yang mendaftarkan paten, maka semakin besar pula teknologi yang dihasilkan oleh sebuah negara.

Invensi (penemuan) melalui penelitian dan adanya implementasi ide manusia yang secara terus menerus akan menghasilkan sebuah karya yang mempunyai banyak manfaat bagi kehidupan manusia. Hasil karya manusia dengan melindungi haknya yaitu melalui pendaftaran paten adalah suatu perbuatan yang baik dan benar. Allah berfirman dalam surat Al-Qashas ayat 14 : "Dan setelah cukup umurnya dan sempurna akalnya, kami menganugerahkan kepadanya hikmah dan ilmu. Dan demikianlah Kami memberikan balasan kepada orang-orang yang berbuat kebaikan".

Islam melalui al-Quran memerintahkan kepada manusia agar menggunakan akal dan pikirannya untuk merenungkan ciptaan Tuhan sebagai bagian dari ibadah. Manusia disuruh banyak berpikir menggunakan akalnya dan bukan banyak tidur. Kewajiban manusia menggunakan akal dan pikirannya untuk mengungkap rahasia bumi dan alam semesta. Perlindungan hukum melalui paten adalah salah satu penghargaan bagi mereka yang mau berkarya. ${ }^{9}$ Paten tentunya bukan semata-mata penghargaan, namun juga motivasi bagi penemu, sehingga nantinya seseorang akan selalu berinovasi guna memenuhi kebutuhan manusia yang selalu ingin berubah menjadi lebih baik.

Pemberian hak eksklusif terhadap penemu paten adalah salah satu penghargaan bagi mereka yang mau berpikir dan berinovasi. Tuhan saja memberikan pahala kepada manusia, apakah salah kalau manusia juga mampu menghargai hasil karya orang lain. ${ }^{10}$

Idiologi matrialistik yang dianut oleh paham Barat tentang perlunya perlindungan

${ }^{9}$ Insan Budi Maulana, Politik dan Manajemen Hak Kekayaan Intelektual, (Bandung: Alumni, 2006), h. 178

Ibid 1 
paten selama 20 tahun, memunculkan hak monopoli dari penemu untuk menjual harga sesuai dengan keinginannya guna mendapatkan keuntungan sebesar-besarnya. Waktu istimewa yang diberikan terhadap pemilik hak paten selama 20 tahun adalah bukan harga mati jika kita merujuk pada ajaran Islam. Islam mengajarkan untuk saling tolong menolong bagi mereka yang membutuhkan dan dianggap tidak mampu. Jadi sangat dimungkinkan bagi negaranegara miskin yang membutuhkan teknologi tidak harus membayar mahal sebelum habis masa perlindungan paten.

Islam tidak mengajarkan monopoli, idiologi kapitalisme dan matrialistik sebagaimana yang sering dianut sebagian besar negara barat dimana sangat menghargai hak individu untuk mendapatkan keuntungan sebesar-besarnya. Islam mengajarkan selalu beramal dengan ilmu yang kita miliki. Namun Allah juga tidak melarang, bahwa manusia diperbolehkan mendapatkan keuntungan dalam bentuk jasa dari apa yang sudah kita peroleh, selama tidak bertentangan dengan syariat Islam. Paten adalah salah satu keuntungan yang dapat diperoleh bagi mereka yang sudah berusaha menemukan sesuatu dan tentunya sudah diperolehnya dengan biaya yang cukup besar pula. Sehingga perlindungan paten adalah suatu bentuk reward sekaligus bentuk ibadah seseorang ketika dia mampu menemukan sesuatu (teknologi) yang dapat bermanfaat bagi masyarakat umum.

Reward dalam bentuk HKI adalah pemberian penghargaan baik secara sosial ataupun ekonomi terhadap seseorang yang sudah berusaha menghasilkan sebuah karya intelektual. Dalam perspektif hukum Islam, sistem HKI dapat dibenarkan. Namun, tidak diperkenankan kalau ilmu yang sudah diperoleh hanya semata-mata untuk memperkaya diri sendiri. Ilmu yang sudah diperoleh juga harus diamalkan dan disampaikan untuk memperoleh manfaat. Sebagaimana disebutkan dalam sebuah hadist:"barangsiapa yang mempelajarai suatu ilmu yang sepantasnya dengan ilmu tersebut untuk mencari ridho Alloh namun ternyata untuk memperoleh kemewahan duniawi niscaya ia tidak akan mencium baunya surga nanti di hari kiamat kelak." (H.R Ibnu majah dengan sanad yang shahih dan Ahmad)

Hadist di atas menjelaskan bahwa monopoli seseorang atas kepemilikan HKI melalui wujud ilmu yang sudah diperolehnya dengan tujuan memungut keuntungan yang sebesar-besarnya dan tidak disertai tujuan mendapatkan ridho dari Allah, maka ilmu yang kita miliki dalam bentuk hasil karya tidak akan mendapatkan kemuliaan di depan Allah. Penulis dalam hal ini berusaha mencoba mengkaji sistem HKI dalam perspektif hukum Islam. Hal ini dilakukan penulis dikarenakan adanya fenomena masih banyaknya pro dan kontra sebagian masyarakat terhadap sistem HKI yang berasal dari konsep negara Barat yang cenderung individualistis.

\section{Perkembangan Umat Islam di Bidang IPTEK}

Dewasa ini, tidak ada suatu kebijaksanan apapun yang dapat menyelesaikan masalah tanpa memperhatikan IPTEK, apakah masalah ekonomi ataupun politik. Nasib manusia pada saat ini dipengaruhi oleh kemampuan manusia mengembangkan, menerapkan, mengendalikan dan menguasai IPTEK. ${ }^{11}$ Sejak masa revolusi industri, teknologi berkembang secara pesat dan tidak dapat dipisahkan lagi dari kehidupan dan peradaban manusia modern. Teknologi bukan hasil sumber daya alam, melainkan hasil pemikiran, karya dan kreatifitas manusia.

Kemajuan IPTEK telah didorong kuat oleh perkembangan gabungan media, telekomunikasi dan komputer, sehingga dunia telah berubah menjadi "kecil" seperti suatu "desa global", dimana orang dengan cepat dapat mengetahui apa yang terjadi

${ }^{11}$ BJ. Habibie, Filsafat dan Teknologi untuk Pembangunan, (Makalah Kuliah Umum di Hadapan Civitas Akademika UI. Depok, 12 Maret 2010), h. 7 
dibagian lainnya dari "desa" itu. ${ }^{12}$ Sesuai dengan ramalan Alfin Tofler bahwa zaman kini dan yang akan datang dunia berada pada "gelombang ketiga", yaitu zaman komunikasi, maka peradaban manusia adalah perabadan Hitech (teknologi tinggi) yang menyebar luas dalam waktu yang singkat. ${ }^{13}$

Salah satu faktor determinan untuk eksis dalam era globalisasi ini, pendayagunaan IPTEKdiyakinimutlakpentingkeberadaanya. Negara maju berlomba untuk melakukan penelitian dan menemukan teknologi, sehingga mereka mampu ekspor teknologi bagi negara berkembang. Globalisasi harus

\footnotetext{
${ }^{12}$ Ibe, M.D, Science Education: Moving on to 21th Century. Paper presented at The Regional Workshop on Strategic planning in Science and Mathematics Education, Penang-Malaysia: RESCAM. Sep. 1995.

${ }^{13}$ John Naisbitt and P. Aburdane, Megatrend 2000: en new Directions for 1990's, Avonbooks, N.Y.
}

menjadi motivasi bagi negara berkembang seperti Indonesia untuk menjadi negara yang mampu melakukan produksi teknologi sendiri, sehingga tidak tergantung impor di negara lain.

Perkembangan negara Islam dan negara denganmayoritasmuslim padaeraglobalisasi initentunyaharusikutberpartisipasiterhadap perkembangan teknologi. Negara Islam tidak boleh pasif dalam pengembangan ilmu pengetahuan dan teknologi. Al Quran telah banyak memberikan pesan agar manusia selalu berpikir menggunakan akalnya untuk menemukan segala ilmu di muka bumi ini. Negara Barat telah menunjukkan eksistensinya melalui riset dan teknologi, sehingga bisa mengungguli negara-negara Islam. Berikut ini daftar paten yang di daftarkan melalui Dirjen HKI berdasarkan negara pengajunya:

\section{Tabel I}

\begin{tabular}{|c|c|c|c|c|c|}
\hline$\cdots \cdot$ & \multicolumn{2}{|l|}{ NEGARA } & 1991-2009 & 2010 & TOTAL \\
\hline 1 & AMERIKA SERIKAT & US & 19406 & 1255 & 20661 \\
\hline 2 & JEPANG & JP & 12639 & 1115 & 13754 \\
\hline 3 & JERMAN & DE & 6282 & 449 & 6731 \\
\hline 4 & INDONESIA & ID & 5839 & 756 & 6595 \\
\hline 5 & BELLANDA & NL & 3857 & 289 & 4146 \\
\hline 6 & swiss & $\mathrm{CH}$ & 3311 & 307 & 3618 \\
\hline 7 & INGGRIS & GB & 3016 & 149 & 3165 \\
\hline 8 & PERANCIS & FR & 2530 & 219 & 2749 \\
\hline 9 & KOREA & KR & 2046 & 185 & 2231 \\
\hline 10 & AUSTRALIA & $\mathrm{AU}$ & 1503 & 95 & 1598 \\
\hline 11 & TATWAN & TW & 1404 & 65 & 1469 \\
\hline 12 & SWEDIA & SE & 1462 & 148 & 1610 \\
\hline 13 & ITALI & IT & 955 & 66 & 1021 \\
\hline 14 & BEL.GIA & $\mathrm{BE}$ & 821 & 77 & 898 \\
\hline 15 & KANADA & $\mathrm{CA}$ & 633 & 55 & 688 \\
\hline 16 & FINILANDIA & $\mathrm{F1}$ & 537 & 64 & 601 \\
\hline 17 & NOR WEGIA & NO & 399 & 36 & 435 \\
\hline 18 & AUSTRIA & $\mathrm{AT}$ & 357 & 25 & 382 \\
\hline 19 & DENMARK & DK & 363 & 45 & 408 \\
\hline 20 & MALAYSIA & MY & 373 & 50 & 423 \\
\hline 21 & INDIA & IN & 353 & 67 & 420 \\
\hline 22 & CINA & $\mathrm{CN}$ & 384 & 89 & 473 \\
\hline 23 & SPANYOL & ES & 247 & 19 & 266 \\
\hline 24 & SINGAPURA & SG & 249 & 24 & 273 \\
\hline 25 & AFRIKA SELATAN & $\mathrm{ZA}$ & 189 & 25 & 214 \\
\hline 26 & HONGKONG & Hк & 118 & 5 & 123 \\
\hline 27 & VIRGINE ISLANDS & v1 & 104 & 0 & 104 \\
\hline 28 & LUXEMBURG & LU & 110 & 10 & 120 \\
\hline 20 & CEI ANOIA RARIT & NZ & 105 & 13 & 118 \\
\hline 30 & ISRAEL & 11 & 102 & 7 & 109 \\
\hline 31 & IRLANDIA & $\mathrm{IE}$ & 107 & 5 & 112 \\
\hline 32 & BRAZIL & BR & 87 & 7 & 94 \\
\hline 33 & RTIISH VIRGIN ISLANI & VG & 76 & 20 & 96 \\
\hline 34 & HUNGARIA & $\mathrm{HU}$ & 69 & 9 & 78 \\
\hline 35 & RUSIA & RU & 63 & 12 & 75 \\
\hline
\end{tabular}


92 I de Jure, Jurnal Syariah dan Hukum, Volume 4 Nomor 1, Juli 2012, hlm. 85-95

\begin{tabular}{|c|c|c|c|c|c|}
\hline 36 & MEXICO & $\mathrm{MX}$ & so & 4 & 54 \\
\hline 37 & THAILAND & TH & so & 3 & 53 \\
\hline 38 & COSTA RICA & CR & 35 & 0 & 35 \\
\hline 39 & BERMUDA & $B M$ & 47 & 7 & 54 \\
\hline 40 & PANAMA & PA & 37 & 2 & 39 \\
\hline 41 & BARBADOS & $\mathrm{BB}$ & 30 & $\mathbf{0}$ & 30 \\
\hline 42 & IRAN & IR & 38 & 5 & 43 \\
\hline 43 & LIECHTENSTEIN & LI & 29 & 1 & 30 \\
\hline 44 & KUBA & $\mathrm{CU}$ & 33 & 1 & 34 \\
\hline 45 & KROASIA & HR & 24 & 1 & 25 \\
\hline 46 & ICELAND & Is & 30 & 2 & 32 \\
\hline 47 & UKRANIA & UA & 26 & 0 & 26 \\
\hline 48 & MONAKO & $\mathrm{MC}$ & 21 & 1 & 22 \\
\hline 49 & PHLLIPINA & $\mathrm{PH}$ & 23 & 1 & 24 \\
\hline 50 & BAHAMAS & BS & 24 & 3 & 27 \\
\hline 51 & CAYMAN ISLANDS & $\mathrm{KY}$ & 22 & 0 & 22 \\
\hline 52 & COTE D'IVOIRE & $\mathrm{Cl}$ & 17 & $\mathbf{0}$ & 17 \\
\hline 53 & KAZAKTAN & $\mathrm{KZ}$ & 17 & 1 & 18 \\
\hline 54 & SLOVENIA & SI & 21 & 0 & 21 \\
\hline 55 & CHILI & $\mathrm{CL}$ & 20 & 2 & 22 \\
\hline 56 & POLANDIA & PL & 15 & 0 & 15 \\
\hline 57 & SAUDI ARABIA & SA & 22 & 2 & 24 \\
\hline 58 & BULGARIA & $\mathrm{BG}$ & 15 & 0 & 15 \\
\hline 59 & UNI EMIRAT ARAB & $\mathrm{AE}$ & 14 & 0 & 14 \\
\hline 60 & ARGENTINA & $A R$ & 15 & 0 & 15 \\
\hline 61 & COOK ISL_AND & CK & 13 & 0 & 13 \\
\hline 62 & SIPRUS & $\mathrm{CY}$ & 23 & 3 & 26 \\
\hline 63 & YUNANI & GR & 13 & 2 & 15 \\
\hline 64 & SRILANKA & $\mathrm{LK}$ & 12 & 0 & 12 \\
\hline 65 & PUERTO RICO & PR & 15 & 0 & 15 \\
\hline 66 & MALTA & MT & 9 & 2 & 11 \\
\hline 67 & VENEZUELA & VE & 8 & 0 & 8 \\
\hline 68 & PORTUGAL & PT & 12 & 1 & 13 \\
\hline 69 & VANUATU & VU & 8 & 0 & 8 \\
\hline 70 & FTHERLANDS ANTII 4 & $\mathrm{AN}$ & 9 & 0 & 9 \\
\hline 71 & CHECHNYA & $\mathrm{CZ}$ & 13 & 9 & 22 \\
\hline 72 & MESIR & EG & 7 & 0 & 7 \\
\hline 73 & TURKI & TR & 15 & 5 & 20 \\
\hline 74 & CEKOSLOVAKIA & CS & 5 & $\theta$ & 5 \\
\hline 75 & SLOVAKLA & SK & 5 & 0 & 5 \\
\hline 76 & YUGOSLAVLA & $\mathrm{YU}$ & 5 & 0 & 5 \\
\hline 77 & SEYCHELLEN & $\mathrm{SC}$ & 5 & 0 & 5 \\
\hline 78 & URUGUAY & UY & 4 & 1 & 5 \\
\hline 79 & GIBRATAR & Gi & 11 & 0 & 11 \\
\hline 80 & SIRIA & SY & 4 & 0 & 4 \\
\hline 81 & CHANEL FSLANDS & $\mathrm{CV}$ & 3 & 0 & 3 \\
\hline 82 & IRAK & 10 & 3 & 0 & 3 \\
\hline 83 & AIPO & $\mathrm{AP}$ & 2 & 0 & 2 \\
\hline 84 & BRUNEI DARUSALAM & $\mathrm{BN}$ & 2 & 0 & 2 \\
\hline 85 & ESTONIA & $\mathrm{EE}$ & 2 & 0 & 2 \\
\hline 86 & KUWATT & KW & 8 & 0 & 8 \\
\hline 87 & LATVIA & LV & 2 & 3 & 5 \\
\hline 88 & PAPUA NEW GUNIEA & $\mathrm{PG}$ & 2 & 0 & 2 \\
\hline 89 & SAINT VINCENT & VC & 2 & 0 & 2 \\
\hline 90 & GRAND CAYMAN & KZ & 2 & 0 & 2 \\
\hline 91 & JORDAN & 10 & 2 & 0 & 2 \\
\hline 92 & OMAN & $\mathrm{OM}$ & 2 & 0 & 2 \\
\hline 93 & COLOMBIA & $\mathrm{CO}$ & 2 & 2 & 4 \\
\hline 94 & DOMINICA & $\mathrm{DM}$ & 1 & 0 & 1 \\
\hline
\end{tabular}




\begin{tabular}{|c|c|c|c|c|c|}
\hline 95 & ECUADOR & EC & 1 & 0 & 1 \\
96 & EPO & EP & 4 & 0 & 4 \\
\hline 97 & GEORGLA & GE & 1 & 0 & 1 \\
\hline 98 & PERL & PE & 2 & 0 & 2 \\
\hline 99 & PAKISTAN & PK & 1 & 0 & 1 \\
\hline 100 & CAICOS ISLANDS & TC & 1 & 0 & 1 \\
\hline 101 & UBEKISTAN & UZ & 2 & 1 & 3 \\
\hline 102 & SAMMOA & WS & 1 & 0 & 1 \\
\hline 103 & LBBANON & LB & 1 & 0 & 1 \\
\hline 104 & QATAR & QA & 1 & 0 & 1 \\
\hline 105 & SIERRA LEONE & SL & 1 & 0 & 1 \\
\hline 106 & KYRGYSTAN & KG & 1 & 0 & 1 \\
\hline 107 & GUYANA & GY & 1 & 0 & 1 \\
\hline 108 & AZERBADIAN & AZ & 2 & 0 & 2 \\
\hline 109 & GUATEMALA & GT & 1 & 1 & 2 \\
\hline 110 & TUNISIA & TN & 1 & 0 & 1 \\
\hline 111 & & TT & - & 0 & 0 \\
\hline 112 & & KE & - & 0 & 0 \\
\hline 113 & & RS & - & 1 & 1 \\
\hline 114 & & SP & - & 0 & 0 \\
\hline 115 & & MA & - & 1 & 1 \\
\hline & JUMLAH & & 71024 & 5830 & 76854 \\
\hline
\end{tabular}

Sumber: $\quad$ http://www.dgip.go.id/ images/documents/hki/paten/Statistik/ permohonan_paten_berdasarkan_negara. pdf

Dari Tabel I tersebut dapat ditunjukkan bahwa permohonan paten masih di dominasi Amerika, Jepang dan Eropa. Data di atas juga menunjukkan bahwa Irak, Mesir, Kuwait dan Saudi Arabia sebagai negara Islam jumlah pengajuan permohonan patennya jauh di bawah negara-negara maju. Minimnya jumlah paten negara Islam yang terdaftar baik di dirjen HKI Indonesia ataupun di PCT dapat menunjukkan betapa minimnya penelitian-penelitian yang dilakukan oleh umat Islam. Al Quran menyuruh manusia untuk selalu berpikir dengan menggunakan kemampuan akalnya dan menggali segala pengetahuan yang disediakan Tuhan di muka bumi dan alam semesta.

Untuk menggali segala pengetahuan Allah yang ada di bumi dan semesta alam, maka Allah menyediakan untuk manusia dua jenis ayat, yaitu:(1) Ayat qauliyah, adalah ayat-ayat yang Allah firmankan dalam kitab-kitabNya; (2) Ayat kauniyah adalah ayat-ayat dalam bentuk segala ciptaan Allah berupa alam semesta dan semua yang ada di dalamnya. Ayat-ayat ini meliputi segala macam ciptaan Allah, baik itu yang kecil (mikrokosmos) ataupun yang besar (makrokosmos). Bahkan diri kita baik secara fisik maupun psikis juga merupakan ayat kauniyah. Allah berfirman dalam surat Fushshilat ayat 53:"Kami akan memperlihatkan kepada mereka tanda-tanda (kekuasaan) kami di segala penjuru bumi dan pada diri mereka sendiri, hingga jelas bagi mereka bahwa Al-Quran adalah benar. Tiadakah cukup bahwa sesungguhnya Tuhanmu menjadi saksi atas segala sesuatu?"

Surat di atas menjelaskan bahwa Allah menunjukkan kekuasaannya bukan hanya melalui ayat-ayat dalam al Quran, namun juga ayat-ayat melalui hasil ciptaannya, seperti bumi dan alam semesta. Allah memberikan perintah pada manusia untuk senantiasa berpikir dan mancari manfaat dari segala ilmu yang sudah diberikanNya. Salah satu diantara sekian banyak perintah 
tersebut adalah firman Allah dalam al Quran sufat Adz-Dzariyat ayat 20-21: "Dan di bumi terdapat ayat-ayat (kekuasaan Allah) bagi orangorang yang yakin. Dan (juga) pada dirimu sendiri. Maka apakah kamu tidak memperhatikan?"

Istilah 'apakah kamu tidak memperhatikan' telah memberikan petunjuk kepada manusia untuk senantiasa berpikir terhadap segala kenikmatan yang Allah berikan yaitu melalui alam dan seisinya. Jika umat Islam memperhatikan ayat tersebut tentunya tidak ada kemalasan bagi manusia untuk selalu berpikir dan memperoleh manfaat dari ilmu yang sudah Allah sediakan. Melalui upaya penelitian yang senantiasa dilakukan oleh umat Islam yang bisa bermanfaat bagi manusia maka umat Islam akan senantiasa meberikan kontribusinya dalam bidang ilmu dan pengetahuan sebagaimana pada waktu kejayaan Islam di masa Abbasiyah.

Indonesia adalah salah satu negara dengan mayoritas umat Islam, kenyataan ini tentunya dapat menjadikan spirit bagi bangsa Indonesia untuk mampu melakukan invensi-invensi yang dapat bermanfaat bagi manusia dan tentunya minimal mampu menjadi negara yang tidak tergantung dengan teknologi asing. Sudah saatnya sekarang merubah budaya para peneliti-peneliti di Indonesia khususnya umat Islam agar melakukan penelitian-penelitian yang sebenarnya, tidak hanya untuk mendapatkan proyek penelitian semata, namun memang seharusnya berubah menjadi penelitianpenelitian berbasis paten, sehingga selain bernilai sosial (kemanfaatan) juga bernilai ekonomis dan tentunya dapat memenuhi kebutuhan IPTEK di era globalisasi.

\section{Kesimpulan}

Invensi (penemuan) melalui penelitian dan adanya implementasi ide manusia yang secara terus menerus akan menghasilkan sebuah karya yang mempunyai banyak manfaat bagi kehidupan manusia. Hasil karya manusia dengan melindungi haknya yaitu melalui pendaftaran paten adalah suatu perbuatan yang baik dan benar sebagaimana dalam firman Allah surat Al-Qashas ayat 14. Paten tentunya bukan semata-mata penghargaan, namun juga motivasi bagi penemu, sehingga nantinya seseorang akan selalu berinovasi guna memenuhi kebutuhan manusia yang selalu ingin berubah menjadi lebih baik.

Islam tidak mengajarkan monopoli, idiologi kapitalisme dan matrialistik sebagaimana yang sering dianut sebagian besar negara barat dimana sangat menghargai hakindividuuntukmendapatkankeuntungan sebesar-besarnya. Islam mengajarkan selalu beramal denganilmu yang kita miliki. Namun Allah juga tidak melarang, bahwa manusia diperbolehkan mendapatkan keuntungan dalam bentuk jasa dari apa yang sudah kita peroleh, selama tidak bertentangan dengan syariat Islam. Dalam perspektif hukum Islam, sistem HKI dapat dibenarkan. Namun, tidak diperkenankan kalau ilmu yang sudah diperoleh hanya semata-mata untuk memperkaya diri sendiri. Ilmu yang sudah diperoleh juga harus diamalkan dan disampaikan untuk memperoleh manfaat dan kemuliaan di depan Allah.

Perkembangan negara Islam dan negara denganmayoritasmuslim padaeraglobalisasi initentunyaharusikutberpartisipasiterhadap perkembangan teknologi. Negara Islam tidak boleh pasif dalam pengembangan ilmu pengetahuan dan teknologi. Al Qur'an telah banyak memberikan pesan agar manusia selalu berpikir menggunakan akalnya untuk menemukan segala ilmu di muka bumi ini. Negara Barat telah menunjukkan eksistensinya melalui riset dan teknologi, sehingga mereka mempunyai jumlah paten yang jauh lebih besar dari negara Islam. Sudah saatnya umat Islam bangkit dari keterpurukan, menjauhi budaya malas yaitu dengan melakukan invensi-invensi melalui penelitian yang berbasis paten. 


\section{DAFTAR PUSTAKA}

A. Raziq Naufal. Umat Islam dan Sains Modern. Bandung: Husaeni, 1978

Bj . Habibie. Filsafat dan Teknologi untuk Pembangunan. Makalah Kuliah Umum di Hadapan Civitas Akademika UI, Depok, 12 Maret 2010.

Ditjen HKI (bekerja sama dengan ECASEAN IPRs Co-operation Programme ECAP II), Buku Panduan Hak Kekayaan Intelektual dilengkapi dengan peraturan perundang-undangan di bidang HKI, Jakarta: Dijen HKI dan ECAP II

Friedman, Thomas L. Memahami Globalisasi. Lexus dan Pohon Zaitun. Bandung: Penerbit ITB, 2002

Ibe, M.D. Science Education: Moving on to 21th Century. Paper presented at The Regional Workshop on Strategic planning in Science and Mathematics Education. RESCAM, PenangMalaysia, 1995

Maulana, Insan Budi. Politik dan Manajemen
Hak Kekayaan Intelektual. Bandung. Alumni, 2009.

John Naisbitt,. and P. Aburdane. Megatrend 2000: en new Directions for 1990's. Avonbooks, N.Y, 1990

Kholistyo, Peradaban Islam pada Masa Dinasti Abbasiyah kemajuan dan kemunduran). Suluk Lembayung blog, 24 januari 2010.

Linsey, Tim, dkk. Hak Kekayaan Intelektual Suatu Pengantar. Alumni Bandung, 2006

Salim Rosyadi. Pandangan Sains dan Teknologi dalam Menghadapi tantangan Dunia Global. www.uinsgd.ac.id, 16 Juni 2011.

Utomo, Tomi Suryo. Hak Kekayaan Intelektual (HKI) di Era Global. Sebuah Kajian Kontemporer.Graha Ilmu. Yogjakarta, 2010

www.dgip.go.id/images/documents/hki/ paten/Statistik/permohonan paten berdasarkan negara 